\title{
Exploring Readiness for Implementing Best Practices: A Mixed Methods Study
}

\author{
Daisy Garcia ${ }^{1}$, Katherine Camacho-Carr ${ }^{1}$, and Weichao Yuwen ${ }^{2}$ \\ ${ }^{1}$ Seattle University \\ ${ }^{2}$ University of Washington
}

July 28, 2020

\begin{abstract}
Rationale. Evidence-based practice (EBP) can improve health care in underprivileged countries. Bolivia's EBP movement is nascent and the factors contributing to better implementation in nursing are unknown. Aim. To explore Bolivian nurses' readiness to engage in EBP while highlighting the facilitators and barriers for pursuing EBP. Method. International collaborators used a sequential explanatory mixed methods study. First, general trends were disclosed via a survey of 170 nurses in La Paz, Bolivia, holding at least a baccalaureate regarding their perceived beliefs about EBP. The survey identified facilitators and barriers for implementing EBP in acute and ambulatory settings. Second, qualitative data was gathered via a focus group of nine nurses with the purpose of enhancing the survey findings. Results. The survey results showed that nurses believe that engaging in EBP can improve their clinical practice. However, the nurses' research behaviors were found to be infrequent. Lack of support from the nurses' clinics and hospitals and from non-nursing professionals were identified as barriers for engaging in EBP. The qualitative results revealed underlying limitations to nurses' clinical practice, including "feeling undervalued." Conclusions. There is a dearth of EBP knowledge among Bolivian nurses stemming from a lack of preparation in EBP environments, including EBP training opportunities. This situation affects nurses' professional dimensions of relational work, power, and collaboration. Collaborative research among educators, professional nursing societies, and local and international organizations could provide initiatives for implementing EBP, based on local health profiles. Key words: international collaboration, evidence-based practice, nurse-multidisciplinary relationship, barriers to EBP.
\end{abstract}

\section{Exploring Readiness for Implementing Best Practices: A Mixed Methods Study}

\section{Background}

Evidence-based-practice (EBP), the conscientious use of the current and best evidence to make decisions about patient care, ${ }^{1}$ may represent a breakthrough that can respond to the health concerns of low- and middle-income countries (LMICs). In Bolivia, an LMIC, the EBP movement is relatively new, but effective health practices might be able to address the country's current pressing health concerns, including decreasing the nation's maternal and infant mortality rates. Currently, 200/100,000 live births and 31/1,000 live births, respectively - numbers that are among the highest in South America. ${ }^{2}$ Additionally, EBP would mitigate the proliferation of sexually transmitted diseases, and prevent adolescent pregnancy complications. ${ }^{3,4}$

Nurses make up the largest sector of the Bolivian healthcare workforce, although baccalaureate-prepared nurses are a smaller group within this labor-pool. ${ }^{5}$ Nurses that hold bachelors' degrees - the product of a fiveyear competency-based curriculum - face particular challenges to improve their practice, primarily stemming from the disconnect between university-based nursing education and the health system organizations where nurses work. Furthermore, there is a paucity of on-site training for nurses to utilize the most recent research; a lack of available location to use relevant medical databases; a lack of infrastructure to develop their own research; and, most importantly, a lack of doctoral prepared nurses leading research. ${ }^{6}$ An international 
tripartite group of researchers from high-income countries (HICs) and LMICs undertook this study to explore Bolivian nurses' readiness, and the specific challenges they face when implementing EBP in acute and ambulatory settings in the city of La Paz.

Collaborating to Assess Best Practices. While collaboration among health practitioners and researchers in Western countries increasingly involves nurses to enhance best practices, ${ }^{7}$ partnerships between Latin American HICs and LMICs are emerging at a slow pace. ${ }^{8}$ There have been several notable HIC-LMIC collaborations, for instance, between Canadian and Colombian scholars who teamed up to assess both the facilitators and barriers for EBP adoption by nurse researchers, educators, and graduate students. Although this study did not involve clinical nurses, it did highlight various needs, including greater communication between academic and clinical practice nurses, increase advanced education, and greater international research collaboration. ${ }^{9}$ The university of South Florida and the University of Panama also partnered to introduce EBP to Panamanian nurse leaders via a conference-based approach, which positively affected nursing curricula and practice. ${ }^{10}$ In Ecuador, nursing researchers investigated faculty and students' beliefs, opportunities, and organizational culture required to implement EBP. This last study showed that the beliefs the participants held about EBP were critical for EBP implementation. ${ }^{11}$ Additionally, in a literature review focused on primary care revealed a number of published studies by Brazilian scholars who identified the most accomplished EBP studies by specialty. ${ }^{12}$ A single search of CINAHL yielded 92 Brazilian EBP-related articles on nursing published since 2006, whereas, in Bolivia, a similar search yielded zero published articles, organizational or government reports about EBP initiatives in the country.

In the last three years, collaboration have taken place between the Higher University of Saint Andrés (UMSA) Nursing School of La Paz, the Bolivian Nurses Association (BNA) and the University College of Nursing (SUCON). This collaborative work has led to the present study. Although similar academic investigations in Western and Eastern countries investigated perceived challenges and barriers of EBP implementation were found; ${ }^{13-16}$ there are differences between those studies and the present work. Here, we endeavored to understand factors preventing the transfer of evidence into practice by including Bolivian nurses' involvement and examine how organizational systems in local contexts affect the nurses' engagement in using evidence to offer quality care. This study used an explanatory, sequential mixed-method design to survey Bolivian nurses about their EBP-associated perceptions and barriers. In phase one, we distributed a survey to 177 nurses. In phase two, nine participants explored the survey findings and discussed factors about the fit between structural systems' context and EBP engagement and implementation.

\section{Theoretical Framework}

Ideas from the transtheoretical model (TTM) and the social transformation (ST) concept drawn from Paulo's Freire's (1972) theory provide the framework for this study. The TTM's concepts of Consciousness Raising, Self-evaluation, andEnvironmental Evaluation ${ }^{17}$ assist in investigating the beliefs and values nurses have, as well as the barriers and facilitators they face when engaging in EBP. Meanwhile, ST, which acknowledges that dialogue-as-humanization, as a collectivist act, enables participants to self-disclose feelings, and share experiences in their own words. ${ }^{18}$ This latter process is intended both to have participants engage in ST dialogues and to spur them into action. Framed by the TTM and ST, this study aims to answer three questions: (a) What are Bolivian nurses' beliefs and values pertaining to EBP? (b) What are the barriers and facilitators that nurses identify when attempting to implement EBP? (c) And lastly, what are the significant relationships between Bolivian nurses' professional and demographics characteristics and the facilitators that allow the nurses to engage in EBP?

\section{Methods}

Following the sequential mixed-methods design, the initial results from the surveys were further explained by data gathered through the focus group. In both, we examined the

participants' relationships to EBP beliefs, values, and behaviors while assessing factors

like years of education, employment, age, and years of research experience. 
The study was approved by the Seattle University Institutional Review Board (file number FY2017-003). The participants signed an informed consent agreement (in Spanish) prior to participating, which expressed the voluntary nature of their participation, their right to refuse to participate or answer questions, and the measures taken to ensure the privacy of their responses.

\section{Setting and Participant Recruitment . Professional nurses (Licenciadas en Enfermeria )}

in three hospitals and five public health centers (Redes de Salud) in La Paz, who had worked for at least two years were invited to participate in the study. Hospitals A, B, and C were all tertiary hospitals with approximately 358,345 , and 160 beds, respectively. The health centers, collectively referred here as D, were located in marginalized neighborhoods. The participants were recruited during brief visits to the study's settings by two Bolivian-trained research assistants (RAs). During the survey period, the RAs could begin to identify the formal and informal leaders, who were to comprise the focus group. These leaders were later invited by e-mail and mail to participate in the focus group. No participant was excluded by any demographic variable (e.g., age, marital status, or sex). The focus group was configured to be homogenous in terms of experience and focus of practice, although each person's characteristics, e.g., age and years of employment, provided for a diversity of opinion during the group sessions, which always had at least seven participants. Participants received means for transportation to motivate attendance and they were also offered small gifts as a gesture of appreciation.

Measures . The survey included: a) demographic questions (Table 1), b) EBP Beliefs (EBPB), c) EBP Implementation (EBPI), and d) the BARRIERS scales. The EBPB scale measures a provider's belief about the value of EBP. ${ }^{19}$ This scale had 16 items, gauged on a five point Likert-type scale, ranging from "strong disagreement $=1$ " to "strong agreement $=5$ ". Total responses could thus range from 16 to 80 . The EBPI scale, containing 18 items, measures the belief and confidence in implementing EBP. It asked the frequency of each item performed, ranging from "0" (zero times)" to "4," (> 8" times). Total scores could range from 0 to 72 . The scales establish appropriate face, content, and construct validity with internal consistency reliabilities of Cronbach's alpha coefficients $>0.90 .{ }^{19}$ The BARRIERS scale assesses the provider's perceived barriers to research utilization. This Likert-type scale is comprised of 29 items under four factors (Table 2), on which they can respond to potential barriers, from 1 (to no extent) to 4 (to a great extent), as well as a non-opinion option. This scale has demonstrated to have high face and content validity with a Cronbach's alpha of $0.65-0.80 .{ }^{20}$ The BARRIERS survey was translated into Spanish following an acceptable process, ${ }^{21}$ and pretested, along with the Spanish version of the EBPB and EBPI survey questionnaires with a group of nurse volunteers $(\mathrm{N}=12)$ having similar characteristics to the study's target population. Similarly, five nurses validated the focus group questions to produce discussion sessions of approximately two hours moderated by a skilled facilitator. The discussion questions were: a) What does evidence-based practice mean to you? b) How do you identify evidence-based interventions? c) What barriers make it difficult to implement EBP? and d) What changes (personal or institutional) do you think are necessary to implement EBP?

Data Analysis . Quantitative data were analyzed in SPSS 19 (IBM, 2010). Here, the descriptive statistics regarding the nurses' demographic and professional characteristics and survey questionnaires were analyzed. The relationships between nurses' demographics and professional characteristics and their identified barriers and facilitators for EBP were examined using chi-square tests for categorical measures and Pearson's $r$ for interval or ratio measures. For the qualitative part, all sessions dialogues, field notes, and the principal investigator's (PI) personal notes were transcribed. The analysis used an inductive approach, beginning close to the data and moving through levels of more abstract analysis to identify the patterns and relationships explaining the phenomena under review. ${ }^{22}$ ATLAS.ti 8.0 was used to identify the repetition of phrases and words using in vivo coding to determine themes, as well as to provide verbatim statements made about those themes. The results were consistent across the three sources of data. For cross-language trustworthiness, the analysis was completed in Spanish - the participants' language. Additionally, transcripts were reviewed by the PI and a doctorate-prepared Bolivian nurse, who negotiated differences. Furthermore, two strategies for validation of data analysis were used: a) investigator triangulation by two bilingual investigators, who independently analyzed the same data; and b) a review of the description of findings by the participants 
themselves.

\section{Results - Phase One}

The sample consisted of 179 nurses holding at least a baccalaureate degree. Each was

employed at least part-time and worked in the same institution at least two years. Most worked in hospital settings $(n=143)$ with the remaining in health centers $(n=36)$. Of the 179 nurses, five were male, and 174 were female (see Table 1 for demographic information).

EBP Beliefs. The summed EBPB scores ranged from 35 to 75 , with a mean of 59.45 (SD $=6.50)$, indicating that nurses had positive beliefs about EBP. However, there is a wide score variation, from $\mathrm{M}=2.64$ (SD $=0.98)$ to $\mathrm{M}=4.27(\mathrm{SD}=0.60)$. The clinical care items $(1,5$, and 9$)$, and items related to their EBP knowledge and their ability to implement it (4, 6, and 15) had high scores, while items regarding beliefs about EBP being difficult and time-consuming (11

and 13) had the lowest scores (Figure 1).

EBP Implementation Behaviors.The mean score for the EBPI scale was 22.4 (SD =

15.09), indicating that nurses implemented EBP behaviors less than three times in the previous eight weeks. Items associated with frequency of using evidence, collecting patient data, and collecting data and generating research questions $(1,3$, and 5$)$ received relatively high scores compared to items asking about accessing and assessing data from the Cochrane and National

Clearinghouse Guidelines data bases (items 12 and 13), which had the lowest scores (Figure 2).

EBP Barriers and Facilitators. The overall mean of the BARRIERS scale $(\mathrm{M}=$

$65.53, \mathrm{SD}=15.74)$ demonstrates that the nurses were more than moderately affected by barriers to utilizing the research in their practices. Specifically, "The Setting" characteristics subscale items scores were higher than the nurse characteristics, quality of research, and research information, all of which were identified as barriers to engage in EBP (Table 2). Conversely, the most distinctive facilitators were those with high scores on the EBPB scale (e.g., the clinical care items $[1,5,9]$ and the nurses' knowledge and ability to implement EBP items [4, 6,15]) (Figure 1), as well as high scores on the EBPI scale (items 1, 2, and 5, associated with using evidence, creating research questions, and collecting data from patients, respectively) (Figure 2).

Relationships among Nurses' Characteristics and Perceived Barriers and Facilitators. Among the facilitators to engagement in EBP, the nurses' respective levels of education were significantly associated with knowledge to improve patients' care (EBPB: item 9) $(F=[5,173]=2.61, p=0.026)$ (Figure 1). Respective education levels also had an effect on collecting data on patients' problems (EBPI: item 5) $(\mathrm{F}=$ $[5,169]=2.30, p=0.05)$. Nurses enrolled in a graduate program had a higher mean score in using evidence to change clinical practice (EBPI: item 1$)(\mathrm{M}=2.22, \mathrm{SD}=1.315)$ compared with those who were not enrolled $(\mathrm{M}=1.75, \mathrm{SD}=1.035) ; t(145)=-2.23, p=0.027)$. Moreover, nurses with experience working in research $(\mathrm{M}=4.31, \mathrm{SD}=0.655)$ had higher scores in the belief that EBP results in the best clinical care compared to those without such experience $(\mathrm{M}=3.97, \mathrm{SD}=0.724), \mathrm{t}(175)=-2.62, p=0.010)$ (Figure 1$)$. Among the barriers, the belief that EBP is difficult to implement (item 13) showed a significant correlation with education level $(F=[5,170]=2.40, p=0.042)$. Regarding accessing the Cochrane database (item 12) showed a significant difference for the mean scores between those who were enrolled in a graduate program $(\mathrm{M}=$ $1.30, \mathrm{SD}=1.331)$ and those who were not $(\mathrm{M}=0.74, \mathrm{SD}=1.081) \mathrm{t}(145)=-2.57, p=0.011)$ (Figure 2). No other characteristics demonstrated significant associations with the facilitators or barrier items on the EBPB and EBPI scales. Of the four BARRIERS scale factors (Table 2), factor 1, containing items associated with setting, was identified as the major barrier to implementing EBP. Overall, there was a positive correlation between Factor 1 and the EBPB total items score, $r=0.16, \mathrm{n}=178, p=0.04$.

\section{Results - Phase Two}

Eight of the nine focus group participants attended the sessions regularly. All were 
female, and identified as either Quechua $(n=6)$ or Aymara $(n=3)$ descendants. Their mean age was 50 years, and, on average, had worked in nursing for 25 years. Five had worked in medical-surgical specialties, two in ambulatory and public health settings, one as a university educator, and another as a hospital administrator. Of the nine, six held management positions, four had graduate-level education, and seven had been involved in research for one or two years. After analyzing the discussion, four themes emerged, as discussed below.

Limited definition of EBP. While the participants did not offer clear statements

defining EBP, they expressed that EBP is a "responsible care" and "guarantees quality of

care" and is "baked up scientifically" and "documented." Similarly, participants' answers

on how they identify EBP interventions were imprecise descriptions and oriented toward applying current protocols, "procedures." These nurses were also limited in providing clear answers when asked about their values and beliefs regarding EBP. As one participant stated, "I think it's unfortunate, but what I see is that a large majority... do not know what EBP is. Because of the overwork... the nurse tends to do a job of compliance and not of logical reasoning... or of doing research." However, in further sessions, participants mentioned that EBP was highly regarded because of what they "heard" or "it is the [current] talk." They also mentioned that there is a "lack of socialization of what nursing based on evidence is" and "of knowing what the advantages [of it] are." The nurses agreed that "inculcating" this knowledge should start in the "undergraduate years, as at this level, if nurses have a bad training, [they] cannot succeed, rise, in the graduate level." "Motivation" was cited as a key factor for socializing EBP as well as "self-criticism," "commitment," "collaboration," "passion for what you do," and "empathy" to gain "recognition among the care team." Moreover, the nurses felt that learning about EBP would assist in their typically "heavy workload," as one voiced, EBP "helps you optimize your time and also feel supported... you feel more secure, you do your job better, more efficient, and obviously there is an internal customer satisfaction."

Absence of support to implement EBP. The "lack of support from administrative authorities" was indicated as the prime barrier to engaging in EBP. One participant stated, "we still do not have [EBP] as a National Policy and less at the level of health ministry... [it] is an urgent need that every professional, in our case, in the field of nursing, should be managing [EBP]." Another participant mused hypothetically about the impact of EBP policies on nursing: "Now, if we gain research positions... from the Ministry of Health, we would reach those positions in each hospital, ... [and] advance a lot, but the vision of our authorities is very different." Similarly, the nurses also expressed their frustration about politically-appointment management positions, designated "a dedo" (arbitrarily), or those given by seniority. A participant stated that "older generations have greater difficulty in being able to engage in EBP, as they are often limited by technological skill." Overall, the nurses identified a broad spectrum of barriers to EBP; their quotes, categorized as personal and organizational barriers, are found in Table 3.

Unsustainable EBP initiatives. When participants were queried about facilitators

necessary to embark on EBP, they described the reverse of nearly all the barriers found in Table 3. For instance, instead of "noncontinuity of nursing initiatives from previous authorities," they proposed "continuity of nursing initiatives..." While these nurses described initiatives previously launched to enhance EBP, they stated that those initiatives were short-lived and administratively under-supported. For example, in one hospital, a survey was conducted by a freshman group of volunteer nurses to assess the level of "knowledge nurses have about phlebitis care," as high prevalence of phlebitis was a concern. However, the respondent stated that some of the nurses did not complete the survey. This apathy was attributed to the fact that the nurses did not understand "that filling out a questionnaire is also contributing in producing evidence." Despite this barrier, "50 nurses... out of the 150 nurses [employed] in the hospital" were surveyed. The results showed that " $70 \%$ had good, $25 \%$ regular, and $5 \%$ deficient knowledge" of phlebitis care. Based on these findings, the surveyors organized: (a) a refresher education program on phlebitis care (this was provided freely in order to motivate attendance, and it also contributed "points" toward the nurses' performance evaluations); and (b) a sub-committee "to sensitize the staff on the topic... for instance, on the frequency of washing [one's] hands." The results of this project "made possible... the installation of hand sanitizer [dispensers] between 
patients' rooms by the hospital." One participant portrays the general sentiment felt by the volunteer nurses regarding this project in this way: "Although the work we've done was not recognized - as complaints reached the management office, because some nurses used hours of their shifts to complete the project- the [fact is that it] has already taken place and has been very beneficial for us... even though we do not know if we will continue doing [research]."

Feelings of disenfranchisement limiting EBP initiatives.Sentiments of being undervalued and experiences of frustration emerged throughout the participants' dialogues. For instance one respondent states that a particular nurse "occupies an administrative planning position in a hospital, but they do not want to recognize her as such; they recognize that she knows how to do the job well, but not as [a] nurse administrator within the establishment, so... our work is not valued." Another participant who worked at a hospital said, "the medical part thinks that they have to direct us in everything, that they have to tell us how many we have to be in a unit and what we have to do." However, nurses agreed that undervaluing of their work also comes from the nurses themselves. "We are selfish; when one person does changes, others [give] criticism: "Why is she doing it in that way? That is wrong. We do not even get paid for it." While almost all participants expressed frustration, some reflected on how "nurses' energy should be channeled" to "be the best," vs. "rivalry" between colleagues. Further, regarding support among the nurses, they stated that learning skills or revisiting "teamwork," looking for strategies to access and "use technology to make work more agile," and being "committed to bettering [ourselves]... and being mentors to students" were "key to transform nursing." Moreover, some felt that the BNA should advocate for "incentives - monetary or not - to support research in nursing." The personal values that the participants emphasized for themselves were to be "aguerrida" (fierce) and to "jerarquizar " (hierarchize) the nursing profession "within the multidisciplinary team."

\section{Discussion}

Our results indicate that, overall, nurses have positive beliefs towards EBPBs,

similar to nurses from HICs, ${ }^{23,24}$ low income, ${ }^{25}$ and other LMICs. ${ }^{26}$ This work also provided unique findings. For example, even though the participants strongly believed in their abilities to implement EBP — seeing it as neither difficult nor time consuming - the rate of the behaviors under review concerning EBP was low, reflecting their lack of EBP understanding. This finding was explained by the nurses' dialogues as the disconnect between what nurses say and what they $d o$. This disconnect-which needs to be addressed-is a well-known concern between nursing care discourse and practice, ${ }^{27}$ and it slows the progress of EBP in the nursing field globally. For Bolivian nurses, this disconnect, in addition to the identified organizational barriers associated to EBP resources development and support by both administrators and medical staff, does not only nullify nurses' involvement with EBP, but also affects important dimensions in their profession, for instance, the relational work dimension, by which nurses learn about one another, gain trust and respect, collaborate, and work as a team ${ }^{28}$ to accomplish goals. The focus group noted that this dimension was absent in their work. The respondents also referred to "destructive criticism," "egoism," and "resistance to change" by seasoned nurses occupying most leadership positions. Those on the focus group also faulted nurses' lack of "altruism and commitment," in fostering relational work. The core values of altruism, commitment, cleanliness, and orderliness have been inculcated ${ }^{29}$ in Bolivia nurses since the 1930s - via an educational model copied from Western countries. However, those values alone would not be enough to improve the needed relational work for effective collaboration among the multidisciplinary teams (including nurses) to deliver safe, quality, evidence-based care. The participants also expressed the "loss of credibility" about "how nurses operate" by the care-team professionals, resulting in a lack of respect and trust by others and a lack of visibility within team-care decision-making processes. In this scenario, the relationship nurses have with patients - their most important source of professional pride, ${ }^{30}$ - is vulnerable to fallibility as well.

Another dimension affecting nurses is power. In nursing, power, has been

defined as "power to" achieve objectives effectively, and "power over" as the ability to influence

others' behaviors. ${ }^{31}$ The nurses in this study shared successful nursing initiatives, by which they achieved their objective of influencing practices. However, these influencing practices were short-lived, and their power in 
these settings was unsustainable due to the lack of organizational support for EBP. In the last decade, researchers have suggested that certain measures, such as changing nurses' perceptions to consider EBP as part of their clinical practice, training supervisors in EBP, ${ }^{32}$ and targeting contextual factors of an organization in terms of its culture, structure, or resources ${ }^{33}$ have the ability to empower nurses. However, none of these measures were present in our participants' workplaces. Contrary to recent findings about nurses having limited power in relation to controlling environments, resources, and over supervisors' competency compared to power on achieving their professional goals, ${ }^{31}$ the nurses in our study were primarily concerned with the latter. They repeatedly discussed that their hospital education committees were led by physicians, and thus the continuing education offered tended to benefit the doctors the most. Perceptions of power among nursing professionals are also affected by other aspects, including age. For instance, studies have reported that younger professionals under 30 years of age ${ }^{31}$ perceive higher levels of group power than those over 30. Our sample consisted mostly of older nurses, and so their responses were the result of an enduring lack of continuing nursing education.

The high scores on items associated with lack of collaboration with physicians and

other staff to implement EPB suggest that collaboration is another affected dimension in the nurses' work environments. Collaboration focuses on the process of collective action to integrate themes and schemes shared by various disciplines with the goal of proposing solutions to complex care problems. ${ }^{34}$ The nurses in this study have called out for more collaboration, not only among themselves but also among the multidisciplinary teams and administrative departments in which they worked. They maintained that they were not valued on par with other health professionals, and therefore, their perspective was discounted. They also felt that they did not have the support from Bolivian professional and scientific organizations to increase their visibility within the care team that would lead to greater integration and collaboration for them. The automatous-like perception physicians have about nursing - a general feeling expressed by the participants - is likely the result of prevalent traditional medical and nursing education in Bolivia.

Having at least some graduate-level education and having research work experience were both correlated with the belief that patients' care would be improved through EBP. The difficulty of accessing data (e.g., from the Cochrane database) was associated with the challenge of implementing EBP. These findings were consistent with other studies. ${ }^{9,15,24}$ The fact that no other associations were found between the participants' demographics and the identified facilitators and barriers might be due to the lack of EBP knowledge and experience among them, thus resulting in contradictory results. However, this study allowed the nurses to voice their own views on their current practices and what they might do differently. They called upon each other to be proactive in getting themselves noticed within the multidisciplinary teams, as well as to strive for more active roles on those teams. Overall, they celebrated the tripartite effort it took to complete this study and expressed their desire to participate in more dialogues to discuss the difficulties they face. In other words, these nurses were looking for assistance to advance the nursing profession as a whole. This help should be one of commitment to investing the necessary time in investigating nursing phenomena in Bolivia, as well as having bilingual researchers, ideally, who come from various collaborating countries. In the present study, the RAs were UMSA faculty, who as part of the research team, received trainings throughout the study process, e.g., instruction offered by the U.S. National Institutes of Health on protecting human research participants (which is found online in Spanish), ${ }^{35}$ which allowed the tripartite collaborative to achieve its goal of capacitating nurses in research.

Several limitations of this study should be discussed. First, there was an underrepresentation of staff nurses in the focus groups, as opposed to nurses in leadership positions. There was also a lack of male nurse participants. When engaging nurses as study participants, it is common that researchers generally get a low response rate. ${ }^{36,37}$ Although this study reached its proposed sample, it is important that specific regional and culturally-based strategies should be applied to update the traditional practice of involving only nurse supervisors. Second, the study was limited in terms of geographical area. Nurses' demographics and attitudes toward EBP can vary in different regions, and this could have affected this study's findings. Thus, the results of this study should not be generalized to other areas or populations. Lastly, the statistical significance was 
set at 0.05. Adjustments for a Type I error in multiple comparisons were not implemented. Nonetheless, we reported all the test statistics and exact $p$ values for an accurate report.

Further research on this topic should unveil the EBP preparedness of nurses at a national level, since regional environmental, socioeconomic, and disease profiles regionally may vary nursing research needs. This could be accomplished using via Web-based surveys, which would likely save data collection time and cost. Investigating the needs of educators and clinical nurses to jointly create institutional EBP cultures could enhance the education of future nurses. Additionally, involving scholars from the host country throughout the research process could help to achieve this goal. Creating an entity embracing educators, clinicians, and nursing organizations to develop strategies for nurses to stay current on their EBP skills is one viable recommendation. Ultimately, the success of nurses can benefit from: a) assessing their internal forces of change to propose EBP activities implementation while maximizing the utilization of current resources and allowing for the smooth adoption of new ones; b) working on a policy proposals to be submitted to the Bolivian Health Ministry to increase leadership in the profession throughout the health-care system; c) creating initiatives to prepare doctoral-level nurses to lead the change; d) enhancing relationships with the global EBP community; e) using social media platforms to inform the public and other health professionals about nursing practices, thus increasing the appreciation, visibility, and reputation of their work; and f) seeking financial support to accomplish various nursing goals through national or foreign grants.

\section{Conclusions}

This study investigated the levels of readiness of Bolivian nurses to engage in EBP, revealed aspects that the nurses considered facilitators and barriers to pursue EBP, and expressed the nurses' own concerns about what they considered to be the current challenges they face. Overall, it is clear that in an LMIC country like Bolivia, where unexpected political and socioeconomic changes may suddenly impact nursing work, nurses need to strengthen their professional standing to withstand forces beyond their control for the benefit of the public's health.

\section{Acknowledgments}

We thank the Sigma Theta Tau International/ The Council for Advancement of Nursing Science for providing the financial support for the study. We also thank the Higher University of Saint Andres, School of Nursing Graduate Program of Bolivia and the Colegio de Enfermeras de Bolivia for their support during the data gathering process.

\section{References}

1. Melnyk BM, Fineout-Overholt E.Evidence based practice in nursing and healthcare: A guide to best practice. Philadelphia: PA: Lippincott Williams and Wilkins; 2007.

2. The World Bank Group. Data: Infant Mortality Rate and Maternal Mortality Ratio. http://data.worldbank.org/indicator/SH.STA.MMRT. Published 2014. Accessed June 20, 2015.

3. Lambert M-L, Torrico F, Billot C, Mazina D, Marleen B, Van Der Stuyft P. Street youths are the only high-risk group for HIV in low-prevalence South American country [Article]. Sexually Transmitted Diseases. 2005;32(4):240-242. doi:doi: 10.1097/01.olq.0000158493.89520.db.

4. Rööst M, Altamirano VC, Liljestrand J, Essén B. Priorities in emergency obstetric care in Bolivia-maternal mortality and near-miss morbidity in metropolitan La Paz [Article]. BJOG: An International Journal of Obstetrics \&S Gynecology. 2009;116(9):1210-1217. doi:10.1111/j.1471-0528.2009.02209.x.

5. Urcullo G, Von Vacano J, Ricse C, Cid C. Health Worker Salaries and Benefits: Lessons from Bolivia, Peru and Chile. 2008. http://www.hrhresourcecenter.org/node/2449.

6. Lange I, Leonhardy K. International column. The need for evidence in nursing practice in Latin America... including commentary by Chang C. Applied Nursing Research. 2006;19(4):220-222. 
7. Hjelm K, Rolfe M, Bryar RM, Andersson B, Fletcher M. Holism in community leg ulcer management: A comparison of nurses in Sweden and the UK. British Journal of Community Nursing. 2003;8(8):353-363.

8. Harrison L, Montenegro G, Malvares S, et al. The network for nursing in child health. Pediatric Nursing. 2008;34(2):113-140.

9. DeBruyn RR, Ochoa-Marín SC, Semenic S. Barriers and facilitators to evidence-based nursing in Colombia: Perspectives of nurse educators, nurse researchers and graduate students. Investigacion \& Educacion en Enfermeria.2014;32(1):9-21.

10. Visovsky C, Maguire DJ, Zambroski C, Palacios L. Bringing evidence-based practice to Latin America: Transforming nursing education and practice. Journal of Continuing Education in Nursing. 2017;48(11):512516. doi:10.3928/00220124-20171017-09.

11. Falconí Morales C, Brito Santacruz CJ, Verkovitch I. Integración de la enseñanza de la práctica de enfermería basada en la evidencia científica [Introducing the teaching of nursing practice based on scientific evidence].Aquichán. 2015;15(4):541-553. doi:https://dx.doi.org/10.5294/aqui.2015.15.4.9.

12. Lacerda RA, Egry EY, da Fonseca RM, et al. [Evidence-based practices published in Brazil: Identification and analysis studies about human health prevention]. Revista da Escola de Enfermagem da USP. 2012;46(5):1237-1247.

13. Majid S, Foo S, Luyt B, et al. Adopting evidence-based practice in clinical decision making: Nurses' perceptions, knowledge, and barriers. Journal of the Medical Library Association. 2011;99(3):229-236.

14. Al-Momani MM, Al-Barmawi MA, Al-Hadid L, Aljabery A. Developing a tool that explores factors influencing the adoption of evidence-based principles in nursing practice in Jordan. Applied Nursing Research. 2016;32:122-127. doi:10.1016/j.apnr.2016.07.004.

15. Dalheim A, Harthug S, Nilsen RM, Nortvedt MW. Factors influencing the development of evidencebased practice among nurses: A self-report survey. BMC Health Services Research. 2012;12(1):367. doi:10.1186/1472-6963-12-367.

16. Younhee K, In-Suk Y. Evidence-based nursing practice and its correlates among Korean nurses.Applied Nursing Research. 2016;31:46-51.

17. Glanz K, Rimer BK, Viswanath K. Health behavior and health education: Theory, research, and practice. 4th ed. San Francisco, CA: Jossey-Bass; 2008.

18. Freire P. Pedagogy of the oppressed (M.B. Ramos, Translated) New York: Herder \& Herder. (Original work published in 1968); 1972.

19. Melnyk BM, Fineout-Overholt E, Mays MZ. The Evidence-based practice beliefs and implementation scales: Psychometric properties of two new instruments [corrected] [published erratum appears in Worldviews Evidence-Based Nursing 2009 1st Quarter; 6(1):49]. Worldviews on Evidence-Based Nursing.2008;5(4):208216.

20. Funk S, Champagne M, Wiese R, Tornquist E. BARRIERS: The barriers to research utilization scale.Applied Nursing Research. 1991;4(1):39-45.

21. Bernal-Vargas MA, Cortés JA, Sánchez R. Adaptación transcultural del cuestionario de puntuación de la neumonía adquirida en la comunidad en pacientes con neumonía leve a moderada en Colombia [Cross-cultural adaptation of the community-acquired pneumonia score questionnaire in patients with mild-to-moderate pneumonia in Colombia]. Biomédica.2017;37(1):104-110. doi:10.7705/biomedica.v37i2.3025.

22. Bradley EH, Curry LA, Devers KJ. Qualitative data analysis for health services research: Developing taxonomy, themes, and theory. Health Services Research.2007;42(4):1758-1772. doi:10.1111/j.14756773.2006.00684.x. 
23. Thorsteinsson HS. Icelandic nurses' beliefs, skills, and resources associated with evidence-based practice and related factors: A national survey. Worldviews on Evidence-Based Nursing. 2013;10(2):116-126. doi:10.1111/j.1741-6787.2012.00260.x.

24. Majid S, Foo S, Luyt B, et al. Adopting evidence-based practice in clinical decision making: Nurses' perceptions, knowledge, and barriers. Journal of the Medical Library Association. 2011;99(3):229-236. doi:10.3163/1536-5050.99.3.010.

25. Oh EG. Research activities and perceptions of barriers to research utilization among critical care nurses in Korea. Intensive \& Critical Care Nursing.2008;24(5):314-322. doi:10.1016/j.iccn.2007.12.001.

26. Adamu A, Naidoo JR. Exploring the perceptions of registered nurses towards evidence-based practice in a selected general hospital in Nigeria. Africa Journal of Nursing 83 Midwifery. 2015;17(1):33-46.

27. Odetola TD, Oluwasola O, Pimmer C, et al. Theory-practice gap: The experiences of Nigerian nursing students. Africa Journal of Nursing \& Midwifery. 2018;20(1):1-13

28. Defrino DT. What is the process of relational work of the nurse? : Dissertations 2126, Loyola University Chicago; January 2016.

29. de Oliden BT, de Millan M. Desarrollo de la educacion de enfermeria en Bolivia [Development of nursing education in Boliva]. Educacion Medica y Salud.1979;13(4):380-388.

30. Sneltvedt T, Bondas T. Proud to be a nurse? Recently graduated nurses' experiences in municipal health care settings. Scandinavian Journal of Caring Sciences.2016;30(3):557-564. doi:10.1111/scs.12278.

31. Katriina P, Sari V, Anja R, Christina S, Paula A, Tarja S. Nursing power as viewed by nursing professionals. Scandinavian Journal of Caring Sciences.2013;27(3):580-588. doi:10.1111/j.1471-6712.2012.01069.x.

32. Hawks JH. Power: A concept analysis. Journal of Advanced Nursing. 1991;16(6):754-762. doi:10.1111/j.1365-2648.1991.tb01734.x.

33. Kueny A, Shever L L, Mckin M L, Titler M G. Facilitating the implementation of evidence-based practice through contextual support and nursing leadership. Journal of Health Care Leadership. 2015(7):29-39.

34. D'Amour D, Ferrada-Videla M, Rodriguez LSM, Beaulieu M. The conceptual basis for interprofessional collaboration: Core concepts and theoretical frameworks. Journal of Interprofessional Care. 2005;19:116-131.

35. Nationa Institutes of Health. Training \& Resources - Human Subjects. https://grants.nih.gov/policy/humansubjects/training-and-resources.htm. Published 2019. Accessed January 29, 2019.

36. VanGeest J, Johnson TP. Surveying nurses: Identifying strategies to improve participation [Article].Evaluation $\& 5$ the Health Professions. 2011;34(4):487-511. doi:10.1177/0163278711399572.

37. Kramer M, Schmalenberg C, Keller-Unger JL. Incentives and procedures effective in increasing survey participation of professional nurses in hospitals. Nursing Administration Quarterly. 2009;33(2):174-187. doi:10.1097/NAQ.0b013e3181a10db6.

\section{Table 1}

Sociodemographic Characteristics of Study Sample $(N=179)$

\begin{tabular}{ll}
\hline Characteristics & Mean $(\mathrm{SD}) / n(\%)$ \\
\hline Age (years) & $39.53(\mathrm{SD}=10.04)$ \\
Ethnicity & $31(17.7)$ \\
Quechua descendant & $139(79.4)$ \\
Aymara descendant & $5(2.9)$ \\
Other &
\end{tabular}




\begin{tabular}{ll}
\hline Characteristics & Mean $(\mathrm{SD}) / n(\%)$ \\
\hline Years worked & $11.97(\mathrm{SD}=9.37)$ \\
Position & $105(59.7)$ \\
Staff nurse & $71(40.3)$ \\
Nurse Supervisor or higher & $111(62.0)$ \\
Education & $62(34.6)$ \\
Bachelor's & $6(3.4)$ \\
Post-bachelor's* & \\
Master's or higher & $87(48.9)$ \\
Currently in a Graduate Program & $91(51.1)$ \\
Yes & $44(24.6)$ \\
No & $51(28.5)$ \\
Specialty Nursing Area of Work & $43(24.0)$ \\
Critical /intensive care & $5(2.8)$ \\
Medical surgery & $36(20.1)$ \\
Other specialized care & \\
Ambulatory care & $138(77.1)$ \\
Public/community health & $39(21.8)$ \\
Research experience & $12.95(\mathrm{SD}=10.58)$ \\
Yes &
\end{tabular}

*Includes diplomado (certificate) in nursing specialties.

Table 2

Scores of the BARRIERS Scale by Factors

\begin{tabular}{ll}
\hline Item & Mean (SD) \\
\hline Factor 1: The Nurse & $2.35(0.65)$ \\
Does not see the value of research for practice & $2.33(1.04)$ \\
Sees little benefit for self & $2.26(1.00)$ \\
Is unwilling to change/try new ideas & $2.35(1.14)$ \\
Feels the benefits of changing practice will be & $2.66(0.99)$ \\
minimal & \\
Does not feel capable of evaluating the quality of & $2.13(1.02)$ \\
the research & \\
Is isolated from knowledgeable colleagues with & $2.53(0.99)$ \\
whom to discuss the research & \\
Is unaware of the research & $2.08(1.06)$ \\
There is not a documented need to change practice & $2.31(1.02)$ \\
Factor 2: The Setting (Organization) & $2.70(0.60)^{++}$ \\
Administration will not allow implementation & $2.76(1.03)$ \\
Physicians will not cooperate with implementation & $3.09(1.01)^{+}$ \\
There is insufficient time on the job to implement & $2.68(1.03)$ \\
new ideas & \\
Other staff do not support implementation & $2.96(0.94)^{+}$ \\
The facilities are inadequate for implementation & $2.65(0.97)$ \\
The nurse does not feel she/he has enough & $2.70(1.01)$ \\
authority to change patient care procedures &
\end{tabular}




\begin{tabular}{ll}
\hline Item & Mean (SD) \\
\hline The nurse does not have time to read research & $2.44(1.09)$ \\
The nurse feels research results are not & $2.46(0.98)$ \\
generalizable to own setting & \\
Factor 3: The Quality of Research & $2.40(0.56)$ \\
Has methodological inadequacies & $2.15(1.00)$ \\
Conclusions drawn from the research are not & $2.18(0.91)$ \\
justified & $2.66(0.99)$ \\
Has not been replicated & $2.25(0.96)$ \\
The literature reports conflicting results & $2.33(1.00)$ \\
Nurse is uncertain whether she/he believes research & \\
results & $2.85(0.98)$ \\
Reports/articles are not published fast enough & $2.42(0.96)$ \\
The amount of research information is & \\
overwhelming & $2.35(0.57)$ \\
Factor 4: Presentation, Research Communication & $2.41(0.79)$ \\
Implications for the practice are not made clear & $2.30(0.87)$ \\
Research reports/articles are not readily available & $2.32(0.92)$ \\
Research is not reported clearly & $2.37(0.89)$ \\
Statistical analyses are not understandable & $2.48(0.93)$ \\
Relevant literature is no compiled in one place & $2.22(1.04)$ \\
Research is not relevant to the nurse's practice &
\end{tabular}

+ Items representing greater barriers to implement EBP

++ Positive correlation with EBPB total score $(p=0.04)$

Table 3

Participant Statements on Barriers to EBP

Personal Barriers

"Lack of commitment [that] leads to lack of knowledge." "Egoism" [among nurses] and "destructive criticism." "Resistance 
Figure 1. EBPB Scores and Facilitators $(F)$ and Barriers $(B)$ by Nurses' Characteristics $(N=179)$

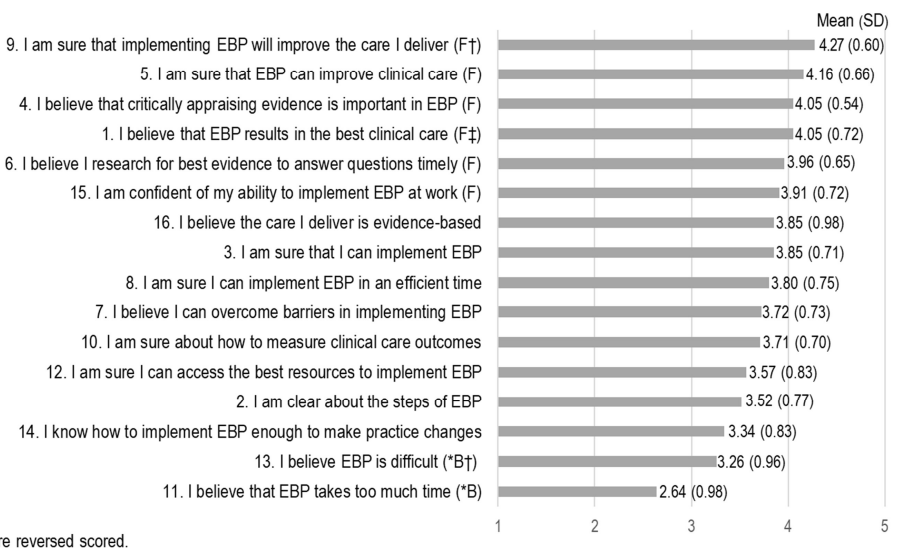

"Items were reversed scored.

†Associated to nurses' level of education ( $F: p=0.026, B: p=0.042$.

FAssociated with nurses having experience working in research $(p=0.010)$.

Refer to Melnyk, B M, Fineout-Overholt, E \& Mays, M Z (2008) for the EBPB scale.

Figure 2. EBPI and Facilitators ( $F$ ) and Barriers $(B)$ by Nurses' Characteristics $(N=179)$

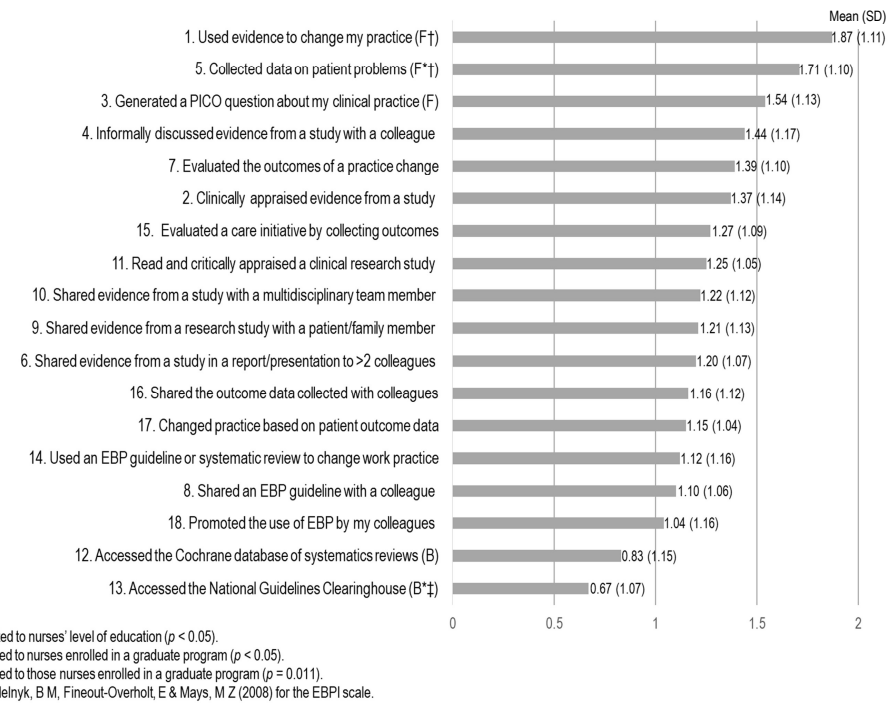

